\title{
Challenges and Barriers Recruitment of Professionals and Management Trainees in a Transitional Situation to the New Normal
}

\author{
Thein Ye Paing ${ }^{1}$, Sein Aung Tun ${ }^{1}$ \\ ${ }^{1}$ Department of Management Studies, Yangon University of Economics, Myanmar \\ Received: October 25, 2021 \\ Revised: November 17, 2021 \\ Accepted: November 29, 2021
}

\begin{abstract}
The purpose of this study is to find out the obstacles faced in recruiting professional and management trainees in the transition situation to the new normal. Competition in the global business world requires company management to be more concerned in managing human resources in it. However, in the new normal situation, several challenges and obstacles in professional recruitment are difficult to attract Candidates with the Right Qualifications, Incomplete Company-Related Information, Ineffective Channels Used, Limited Access to Required Devices and others. All recruitment processes including selection can be done online, the right solution during a pandemic.
\end{abstract}

Keywords: Management Trainee, Professional, New Normal

\section{Introduction}

During the present new normal transition phase, several businesses are experiencing significant uncertainty. This is because every business needs re-hire experts and management trainees to ensure worker retention and to optimize the company's quality. This is owing to the large number of layoffs or staff layoffs that occurred when the epidemic struck the whole planet. Gradually, some businesses are reviving their operations to the point that they require more skilled human resources in their respective professions.

Competition in the global corporate environment compels management to place a higher premium on human resource management (Rees \& Smith, 2021). Currently, businesses require not just human resources to fulfill demands, but also human resources with enough competence and a high level of commitment. Human resource management processes encompass recruiting and selection, training and development, pay, and termination, as well as a variety of employee behaviors that might affect the work process.

Effective staff management begins with effective recruiting management. Recruitment is a critical component of human resource management (Chelladurai \& Kerwin, 2018). The choice to acquire new personnel is critical for every business. The business must be able to attract applicants that are not only qualified for the position at hand, but also fit the company's culture. Recruiting the best individuals for the job has become a difficulty in the modern day. The organization must be able to attract a large number of potential employees to fill open positions.

To make the process of recruiting prospective employees easier, the organization needs amass a sizable database of applicant data (Campion et al., 2019). When a corporation has a data repository with a large number of prospective applicants, recruiters may easily choose candidates from the data set (Kang et al., 2019; Laumer et al., 2015). 
In an ideal world, a recruiting process would collect data on applicants selected for further selection, allowing the organization represented by recruiters to readily choose prospective employees as needed. Numerous techniques and approaches utilized in recruiting must be tailored to the qualities of the targeted potential applicants in order to pique their interest in reading job adverts (Orrick, 2008). Additionally, it is anticipated that prospective individuals would be motivated to apply for the open post.

Several of the above arguments are perfect circumstances for a recruiting procedure. Recruitment has become more difficult in recent years. Researchers in the field of human resources have discovered that executing a recruiting process is not as simple as it appears (Wright et al., 2001). The issue at hand is selecting the most effective approach for recruiting applicants who match the required requirements. Recruiters cannot conduct direct recruiting, particularly during the present new normal transition phase, due to ongoing concerns about the spread of covid-19. Some organizations have difficulties and impediments in recruiting personnel, including insufficient information about companies, putting applicants who are not a match for the job post and qualifications of the candidate, and a variety of other issues (Feldman \& Klaas, 2002).

Concerning the ways usually used to draw potential applicants' attention, it is mentioned that a variety of strategies are frequently utilized, including posting job adverts on job portals, mass media, job fairs, and university recruiting, as well as performing referral programs. All of these strategies fall under the category of external recruiting. Meanwhile, internal recruitment strategies entail the promotion, transfer, or transfer of personnel. Each organization has its own unique recruitment strategy, based on its unique needs and circumstances. The goal of this study is to ascertain the barriers to recruiting professionals and management trainees throughout the period of transition to the new normal.

\section{Challenges and barriers to recruiting workers during the new normal}

The following are some of the difficulties encountered by human resource development in attracting professional and management trainees during a pandemic.:

\section{Build a strong employer brand}

The majority of job searchers, up to $75 \%$, believe that the company brand is critical. Therefore, if job searchers view your brand and get disinterested, they will not hesitate to apply for a position. Indeed, they would rather be unemployed than work for a firm with a less respectable name. Creating informative and appealing websites and blogs is one of the most effective strategies to establish a strong company image.

\section{Lack of Qualified Candidates}

Today, the most significant recruitment problem is a talent scarcity. According to a National Federation of Independent Business research, 87 percent of human resource professionals encounter little or no eligible applications for open positions. Coupled with ever-increasing 


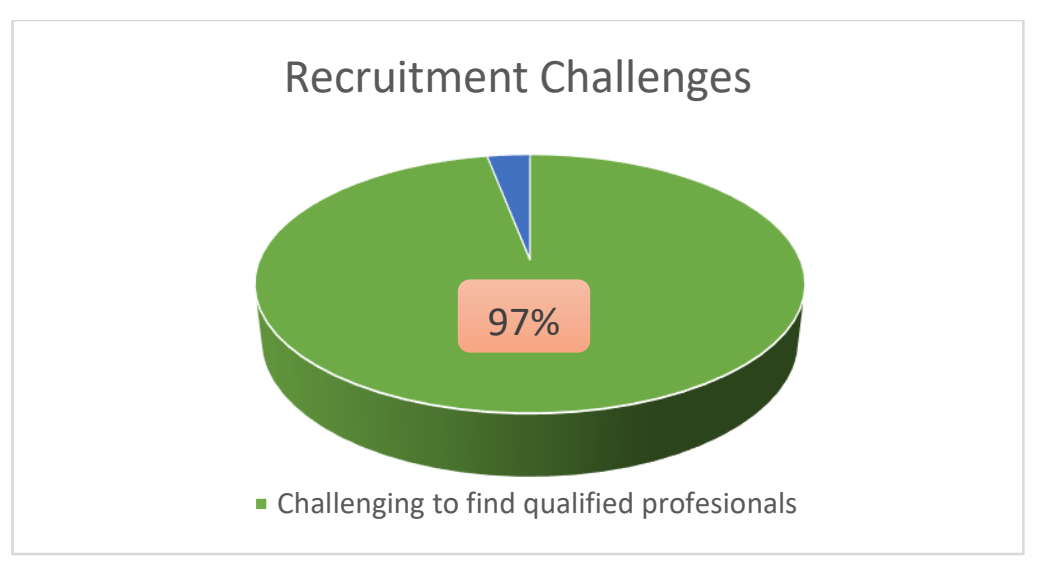

Figure 1. Recruitment Challenges

\section{Source: Robert Half}

According to a Glassdoor research, $76 \%$ of hiring managers acknowledge that the most difficult part of their job is attracting the appropriate candidates. As a result, much time was lost as the recruiting staff was required to review hundreds of incoming $\mathrm{CVs}$, even if they did not come from competent individuals who met the company's needs. However, it soared to 97 percent of candidate mismatches during the epidemic. A critical step in overcoming this is to provide as precise a job description as possible for the job vacancies that you distribute (Mitchell et al., 1999). This enables candidates to assess their own capabilities, which results in them being more selective when applying for employment.

Not only finding job is difficult, but so is hiring staff. Additionally, the organization is encountering roadblocks and hurdles in acquiring the most qualified personnel. As a result, you must carefully plan your recruitment strategy to ensure that your organization attracts the talent it need. There will always be obstacles, but they can be overcome.

Recruitment has been limited throughout this epidemic. Interviews with applicants who have completed the previous selection step are required to be conducted through video call (Wolff \& Burrows, 2021). yet, they remain distinct. We were able to witness firsthand what sort of person he was and also more clearly analyze his personality through face-to-face conversations. Inevitably, we must adapt and develop alternate exams to evaluate what we cannot evaluate face to face.

Along with some of the aforementioned barriers, professional recruiting, particularly online recruitment, has technical challenges. When undertaking an online recruitment process, some of these factors frequently create impediments. The following are the most often committed errors throughout the online recruitment process.

\section{Reaching Candidates Wider}

Due to the scarcity of competent applicants, you as a recruiter must be able to reach out to a broader pool of talent. You must seek out these prospects on social media in order to build your brand community. The trick is to ensure that the job openings you publish are distributed across all channels, from social media to in-person events such as job fairs. This increases your chances of locating the talent you seek.

\section{Targeting Passive Candidates}

If present trends continue, there will be no more job seekers, only passive prospects. These are individuals who are not actively seeking job. According to LinkedIn data, passive talent accounts for $70 \%$ of the worldwide workforce. Only $30 \%$ are job searchers that are actively seeking jobs. However,

Copyright @ 2021, Journal of Asian Multicultural Research for Economy and Management Study, 
$90 \%$ of passive candidates are ecstatic when notified of a new job position. Therefore, make a concerted effort to increase your job's visibility.

\section{Incomplete Company Information Reported}

Certain job openings are published via social media, and often a great deal of information is omitted. If the organization does not explicitly specify the names and positions available, potential applicants may have a difficult time obtaining specific information from the company. As a result, it is strongly suggested to supply accurate information about firms and vacant employment positions.

\section{Long recruitment process}

Most organizations employ many job postings to assist in the recruiting process, such as LinkedIn, job portal sites, or the online job fairs that are frequently organized today. However, a typical error made by the recruiting team during this process is to determine the channel's efficacy purely on the basis of the number of candidates who have seen the job opening. Indeed, the number of applicants that apply directly through the platform is a better predictor than the number of candidates who see and meet the vacancy's qualifying requirements. Additionally, the recruiting process typically takes a long time since a large number of individuals access open recruitment, which results in some applicants applying to other organizations. During the pandemic, it increased to 63 percent of candidates attempting to apply in several locations that were advertising job openings.

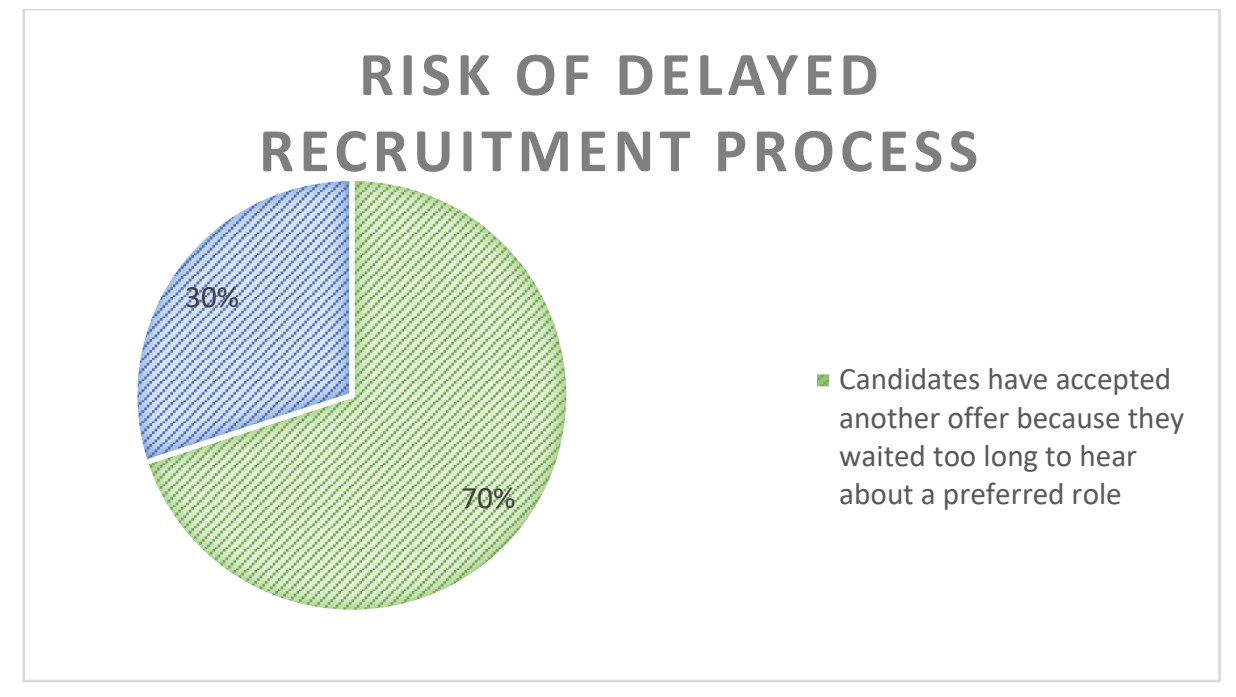

Figure 2. risk of delayed recruitment process

Source: Robert Half

\section{Limited Access to Required Devices}

When performing an online recruiting process, a common issue is that potential applicants who wish to conduct an interview may complain about not having access to the necessary equipment. This is entirely conceivable as a result of restricted tools and insufficient internet connectivity. To address this, the recruiter might attempt to give alternates that will help the interview process flow more smoothly. For instance, by conducting interviews via WhatsApp conversations, which are more familiar to a large number of individuals.

\section{Placing a Candidate Does Not Match the Job Position and Skills of the Candidate}

Placing applicants with highly specialized talents in the most suitable and acceptable employment roles is difficult, much more so when the skills are extremely specialized. Indeed, some employers will simply place the individual in a position that is incompatible with their

Copyright (C) 2021, Journal of Asian Multicultural Research for Economy and Management Study, 
acquired abilities and available positions. This has the ability to undermine the employee's effectiveness. The recruiting agency's first task should be to thoroughly describe the job description that will be performed, and the second step should be to seek for applicants with the appropriate abilities (Wise, 1987).

\section{Not Providing Clear and Periodic Information to Candidates}

Time is critical and extremely important; the limited time available is frequently the reason why some human resource practitioners are unable to provide candidates with up-to-date information. If any information in the recruiting process is unclear, this places a premium on the candidate's experience during the recruitment process. For recruiters interested in learning about a prospect's perception of their experience, they can create a survey asking the candidate to rate various aspects of the recruiting process on a specific scale. Recruiters may use the findings of this survey to gain a better understanding of what needs to be addressed in their business's recruiting process in order to provide a better applicant experience and to help establish a stronger brand image.

\section{Overcoming problems and obstacles in professional recruitment during the new normal transition period}

\section{Social Distancing Friendly}

The extra advantage of GreatDay Recruiting is that all recruitment processes, including selection, can be conducted online, which is the ideal answer during a pandemic, right? HRD simply needs to post job openings; the system will handle the rest. Information regarding the number of applicants, applications that have been examined, and applications that have been rejected will be updated automatically. HRD may also organise interviews directly with applicants whose applications have passed the selection process. Apart from being convenient for businesses, the characteristics of GreatDay Recruitment are also convenient for job searchers. A single application may be used to obtain information about job openings, transmit curriculum vitae (CV) in video format, and track the status of job applications. Locate jobs more quickly and conveniently.

\section{Effective and Efficient through Your Mobile}

As previously noted, the primary issue with the recruiting process is the amount of time and money required. GreatDay Recruiting is the solution to this problem since it enables the recruitment process to be conducted anywhere and at any time, from applicant selection to conducting interviews by mobile. Additionally, there is no additional charge for using this service.

\section{Automatic Screening and Filtering}

GreatDay HR simplifies the process of defining the criteria for the talent you require. Simply enter the parameters you want, and the system will automatically filter out applications that meet your requirements. Additionally, you may incorporate a pre-test in the form of generic questions to expedite the applicant screening process and ensure that only candidates who fulfill the requirements advance to the interview stage. There is no reason to waste time interviewing those who do not qualify. Naturally, conserve energy, time, and money.

\section{Neatly Stored and Structured Data}

The administration and storage of data is unquestionably tidy and organised when using a cloud-based storage solution. There is no need to worry about application data loss, differentiating applicants who advance to the next step from those who do not, or distinguishing 
applicant data that has been examined. Everything is automatically stored and arranged in a logical manner.

\section{Conclusion}

Finding competent employees is the number one recruiting difficulty today due to the new normal transition conditions. The primary strategy for attracting top people is to enhance the company's image and expand its audience. This will boost your chances of locating the talent you want. Recruitment is limited during this epidemic. Interviews with applicants who have completed the previous selection step must take place online through video conference. Recruiters will undoubtedly have to adjust and develop different exams to evaluate prospects. All recruiting activities, including selection, may be carried out online, which is the optimal approach in the event of a pandemic. HRD need simply to post job openings and sort data such as examined applications; rejected applications will be updated automatically by the system.

\section{References}

Campion, M. C., Campion, E. D., \& Campion, M. A. (2019). Using practice employment tests to improve recruitment and personnel selection outcomes for organizations and job seekers. Journal of applied psychology, 104(9), 1089.

Chelladurai, P., \& Kerwin, S. (2018). Human resource management in sport and recreation. Human Kinetics.

Feldman, D. C., \& Klaas, B. S. (2002). Internet job hunting: A field study of applicant experiences with on-line recruiting. Human Resource Management: Published in Cooperation with the School of Business Administration, The University of Michigan and in alliance with the Society of Human Resources Management, 41(2), 175-192.

Kang, X., Dong, F., Shi, C., Liu, S., Sun, J., Chen, J., ... \& Zheng, H. (2019). DRAMP 2.0, an updated data repository of antimicrobial peptides. Scientific data, 6(1), 1-10.

Laumer, S., Maier, C., \& Eckhardt, A. (2015). The impact of business process management and applicant tracking systems on recruiting process performance: an empirical study. Journal of Business Economics, 85(4), 421-453.

Mitchell, K. E., Al Levin, S., \& Krumboltz, J. D. (1999). Planned happenstance: Constructing unexpected career opportunities. Journal of counseling \& Development, 77(2), 115124.

Orrick, D. W. (2008). Recruitment, retention, and turnover of police personnel: Reliable, practical, and effective solutions. Charles $\mathrm{C}$ Thomas Publisher.

Rees, G., \& Smith, P. (Eds.). (2021). Strategic human resource management: An international perspective. Sage.

Wise, A. E. (1987). Effective teacher selection: From recruitment to retention. The Rand Corporation, 1700 Main Street, PO Box 2138, Sanata Monica, CA 90406-2138.

Wolff, M., \& Burrows, H. (2021). Planning for virtual interviews: residency recruitment during a pandemic. Academic pediatrics, 21(1), 24-31.

Wright, P. M., Dunford, B. B., \& Snell, S. A. (2001). Human resources and the resource based view of the firm. Journal of management, 27(6), 701-721. 